\title{
Single Odor-sensitive Channels in Olfactory Receptor Neurons Are also Gated by Cyclic Nucleotides
}

\author{
Stuart Firestein, ${ }^{1}$ Frank Zufall, ${ }^{2}$ and Gordon M. Shepherd ${ }^{1}$ \\ 'Section of Neurobiology, Yale University Medical School, New Haven, Connecticut 06510 and 2 Physiological Institute, \\ Technical University Munich, 8000 Munich 40, Germany
}

\begin{abstract}
Olfactory transduction is thought to occur by processes that are mainly restricted to the specialized cilia emanating from the distal end of the receptor neuron's single dendrite. The involvement of a cAMP-based second messenger system seems likely, and a cyclic nucleotide-sensitive current has been recorded in patches of membrane from the cilia. However, the small diameter of the cilia and the high density of channels within the membrane limit the application of the patch recording technique in the cilia. We have found that the CAMP-sensitive channels also exist at a much lower density within the far more accessible dendritic membrane. Recording from on-cell patches, we have observed singlechannel activity in response to extracellularly applied odor substances. The channels have a single-channel conductance of $40 \mathrm{pS}$ and a reversal potential near $0 \mathrm{mV}$. These same channels are activated by treatments that elevate intracellular cyclic nucleotide concentrations. The results provide a direct demonstration that the cyclic nucleotide-gated channel is the conductance pathway for the odor-elicited current.
\end{abstract}

Vertebrate olfactory receptor neurons respond to odors with an inward cationic current that depolarizes the membrane and elicits action potential generation (Trotier and MacLeod, 1983; Firestein and Werblin, 1989; Kurahashi, 1989; Firestein et al., 1990). The site of transduction is mainly within the specialized cilia that emanate from the distal end of the cell's single dendrite (Firestein et al., 1990). Within the ciliary membrane are the components of a second messenger system, including a G-protein (Pace and Lancet, 1986; Jones and Reed, 1989) and an adenylate cyclase (Pace et al., 1985; Sklar et al., 1986; Dhallan et al., 1990), together with the ion channels presumably underlying the depolarizing conductance (Trotier and MacLeod, 1986; Kurahashi, 1990; Firestein et al., 1991). From the best current evidence, it appears that this conductance is activated directly by either cAMP or cGMP (Nakamura and Gold, 1987). A clone of the ion channel has recently been isolated by utilizing a cDNA probe derived from the cGMP-gated channel found in photoreceptors (Dhallan et al., 1990). The two channels share exten-

\footnotetext{
Received Apr. 3, 1991; revised June 12, 1991; accepted June 20, 1991.

This work was supported by NIH Grant NS 10174-18 (G.M.S.), Office of Naval Research Grant N00014-90-J-1432 (S.F.), and Deutsche Forschungsgemeinschaft (F.Z.).

Correspondence should be addressed to Stuart Firestein, Section of Neurobiology, Yale University Medical School, 333 Cedar Street, New Haven, CT 06510.

Copyright (C) 1991 Society for Neuroscience $0270-6474 / 91 / 113565-08 \$ 05.00 / 0$
}

sive sequence homology and are apparently similar functionally as well (Kaupp et al., 1989; Dhallan et al., 1990).

Electrophysiological investigation of the channels has been hindered by rather unfavorable recording conditions. The native channel exists at apparently high densities on the cilia so that even in excised patches it is impossible to resolve single-channel activity (Nakamura and Gold, 1987). Furthermore, the small diameter of the cilia, between 0.1 and $0.25 \mu \mathrm{m}$, and their waving motion make it extremely difficult to attain successfully a gigaohm seal on the ciliary membrane. Thus, there has been only one published study utilizing excised patches of native membrane, and this work analyzed only the macroscopic currents due to the action of cyclic nucleotides (Nakamura and Gold, 1987).

The use of cloned channels offers some hope of circumventing these difficulties, but in the first report of this method, channel expression was so high that only macroscopic currents in the nanoamp range could be observed in excised patches (Dhallan et al., 1990). Additionally, the channel was expressed in a nonsensory (indeed non-neuronal) cell, so that its physiological role in olfactory transduction could be not investigated directly.

An alternative strategy is to record from patches of membrane in which the channels exist at a low density. In their original report, Nakamura and Gold (1987) mention that cyclic nucleotide-gated channels were also detected on patches excised from the dendrite and soma. Suzuki (1989) has also shown that cAMPsensitive channel activity can be recorded from soma patches. It has not been known, however, whether these channels are directly involved in the transduction of sensory signals.

In this study, we have used this strategy to record from oncell patches of dendritic membrane in isolated olfactory receptor neurons. The cells were similar to those utilized in earlier wholecell recordings, which responded to pulsed odor stimuli with an inward cationic current (Firestein et al., 1990). We have found that the channel density in the dendrite is sufficiently low that it has been possible to record and measure single-channel events. The results show that odor-sensitive ion channel activity can be recorded from the dendritic membrane near the origin of the cilia and that these channels are the same as those gated by cAMP. The accompanying article (Zufall et al., 1991) extends the analysis of these channels and characterizes their cyclic nucleotide-regulated activity.

\section{Materials and Methods}

Olfactory receptor neurons were isolated from the nasal epithelium of adult-phase tiger salamanders (Ambystoma tigrinum) by methods described in detail previously (Firestein et al., 1990). The cells were maintained in a Ringer's bath including (in $\mathrm{mM}$ ) $\mathrm{NaCl}, 120 ; \mathrm{KCl}, 2.5 ; \mathrm{CaCl}_{2}$, 


\section{A}

\section{B}
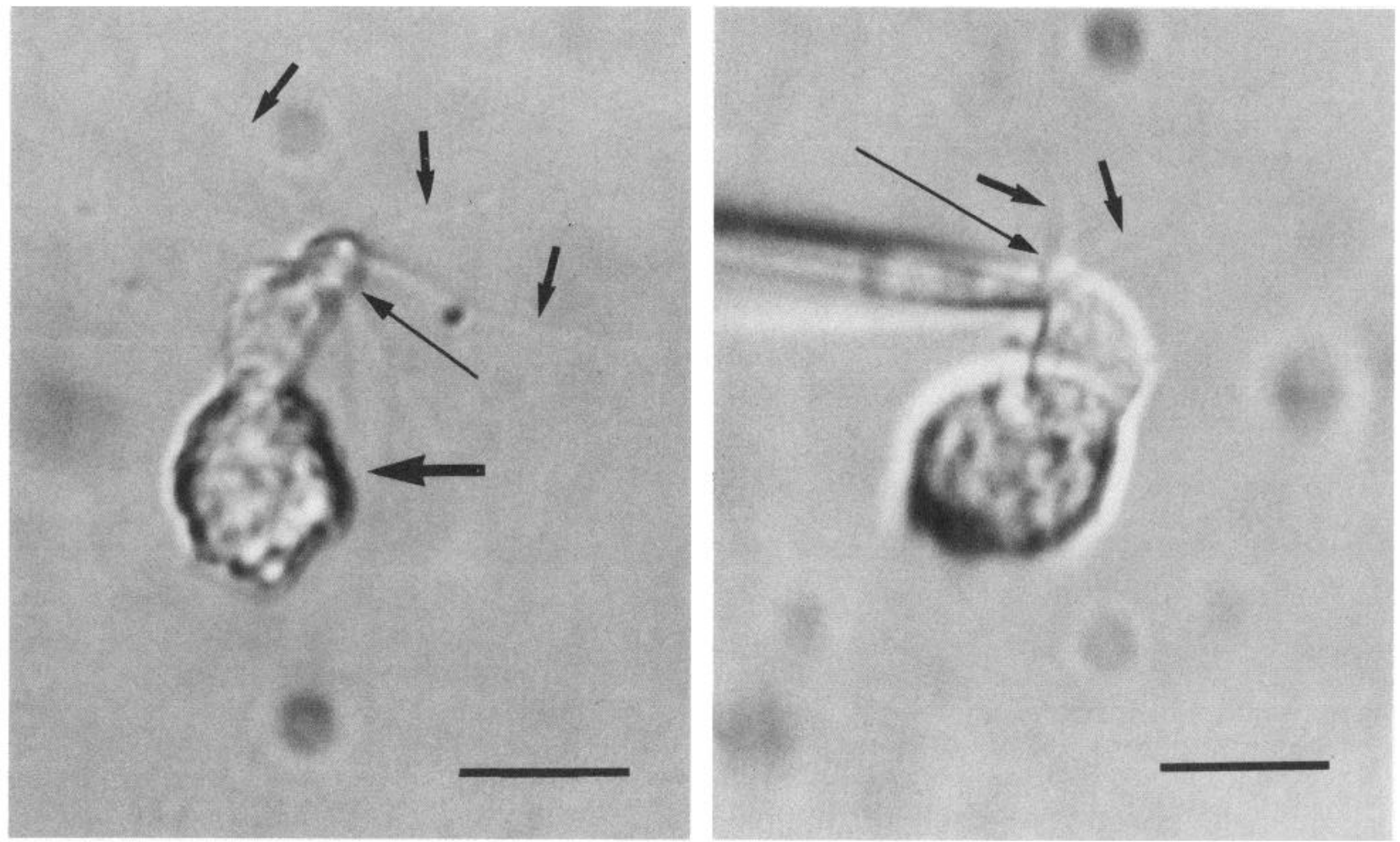

Figure 1. Photomicrographs of isolated olfactory receptor neurons. A, Typical receptor neuron with a soma (large thick arrow) from which a single dendrite extends from the apical region. The dendrite ends in a knob-like swelling (long thin arrow) from which emanate the cilia (short arrows). $B$, Position of the patch electrode on the receptor neuron in a typical recording. The membrane patch was located at the distal end of the dendrite or on the knob (long thin arrow) at the base of the cilia. The cilia (short arrows) were typically 10-50 $\mu \mathrm{m}$ in length and were motile. Only the proximal portion of the cilia near the knob is in the plane of focus. Scale bars, $20 \mu \mathrm{m}$.

$1.0 ; \mathrm{MgCl}_{2}, 1.6 ;$ HEPES, 10 ; glucose, $5 ; \mathrm{pH}$ 7.6. In this medium, cells remained viable for up to $12 \mathrm{hr}$ postmortem, as determined by the continued motility of the cilia and the presence of normal-appearing voltage-gated currents (Firestein and Werblin, 1987). For most experiments, the $\mathrm{NaCl}$ was replaced by equimolar choline chloride (see $\mathrm{Re}-$ sults).

Odor stimuli were prepared as described previously (Firestein and Werblin, 1989) by mixing amyl acetate, acetophenone, and cineole in normal Ringer's solution to a concentration of $1 \mathrm{~mm}$. The stimuli were delivered by pressure ejection from a pipette with a $2 \mu \mathrm{m}$ tip opening placed within $25 \mu \mathrm{m}$ of the cell. From previous calibrations, we estimate that the concentration of each odor reaching the cell was on the order of $10-100 \mu \mathrm{M}$ and that the odor solution reached the cell within 2-10 msec of pressure application (Firestein and Werblin, 1989).

Other pharmacological agents were dissolved in Ringer's solution and perfused into the bath. These included isobutylmethylxanthine (IBMX), which was prepared as a stock solution in dimethyl sulfoxide (DMSO) and diluted to final concentrations of 50-500 $\mu \mathrm{M}$. At these dilutions, the DMSO was present at $0.5 \%$; at this concentration, the DMSO by itself had no effect on the cell. Membrane-permeable cyclic nucleotide analogs, 8-bromo cyclic GMP and AMP (obtained from Sigma), were dissolved directly in the Ringer's solution to a final concentration of 1 $\mathrm{mm}$. Solutions were prepared fresh daily. The entire $0.5 \mathrm{ml}$ bath volume could be changed in approximately $1.5 \mathrm{~min}$.

Recordings were made using the cell-attached configuration of the patch clamp (Sakmann and Neher, 1984). Electrodes were fashioned from Corning 5072 glass and fire polished to tip resistances of $10-12$ $\mathrm{M} \Omega$. The pipette solution contained (in $\mathrm{mm}$ ) $\mathrm{NaCl}, 120 ; \mathrm{KCl}, 2.5 ; \mathrm{CaCl}_{2}$, 1.0; EGTA, $5 ; \mathrm{Na}_{0.5}$ HEPES, 10 . Single-channel currents were recorded using an Axoclamp patch-clamp amplifier (Axon Instruments) and stored on videotape. For analysis the signals were sampled at $2.5 \mathrm{kHz}$ and digitized at $10 \mathrm{kHz}$ on an IBM 286 computer using pCLAMP software (Axon Instruments).

\section{Results}

The data reported here were obtained from on-cell patch recordings from 21 different receptor neurons. Isolated cells with short dendrites were chosen for study. In some cells, the dendrite had retracted completely and the cell appeared as a round or pear-shaped soma with cilia emanating from one side. All cells recorded had motile cilia. In previous studies using whole-cell patch clamp, both voltage-gated (Firestein and Werblin, 1987) and odor-induced (Firestein and Werblin, 1989; Firestein et al., 1990) macroscopic ionic currents have been recorded in similarappearing cells. Recording sites were either on the dendrite or, in those cells with no clear division between soma and dendrite, within a few microns of the base of the cilia (Fig. 1).

\section{Responses to odor pulses}

Of the 21 cells successfully patched, 13 responded to pulsed odor stimulation with bursts of channel openings. In 10 of the 13 patches, single-channel openings with no current superpositions were detected; in the other three, up to three superpositions were observed. It was common for recording conditions to remain stable for $30-45 \mathrm{~min}$, during which time responses to 15-30 odor pulses could reliably be elicited. In addition to 
A

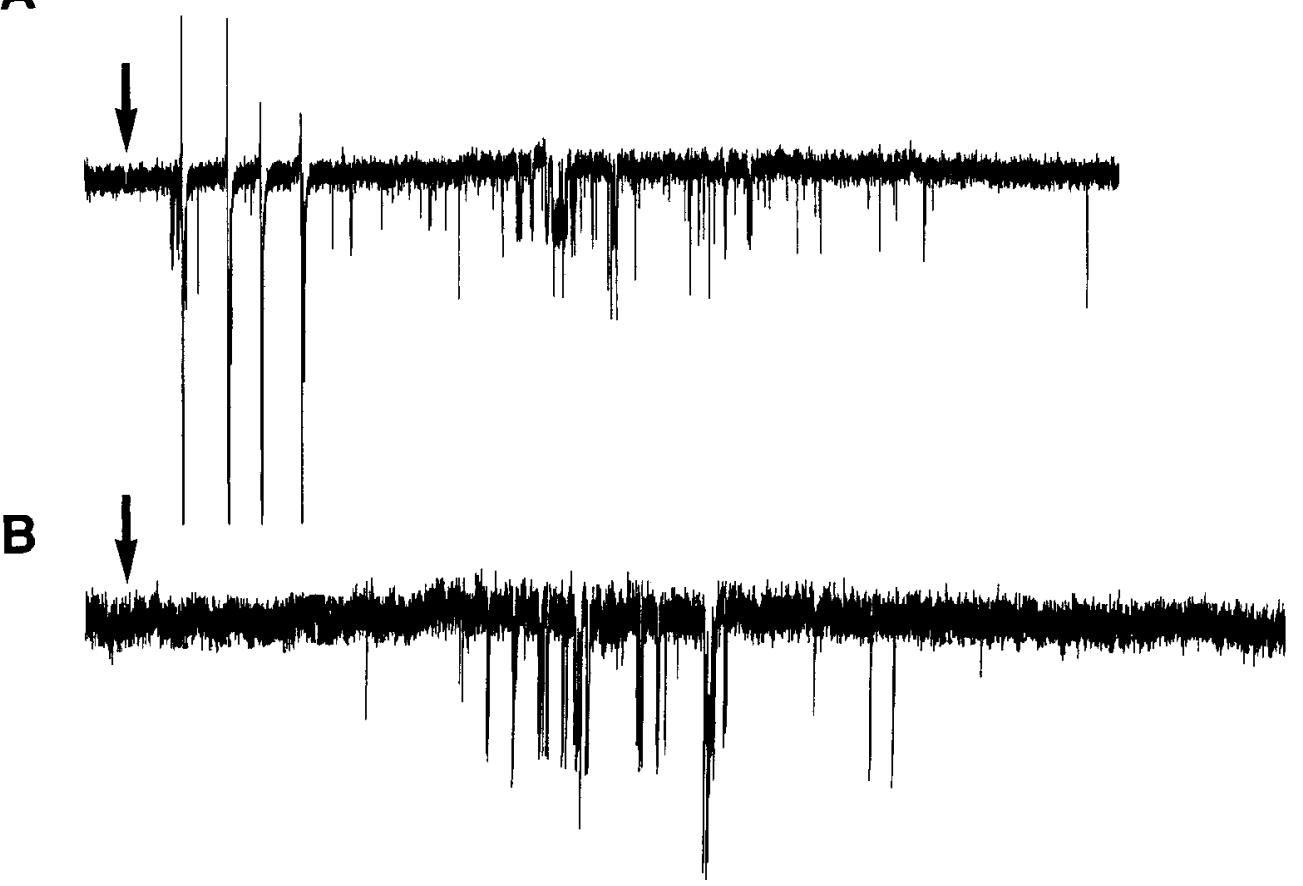

\section{C}
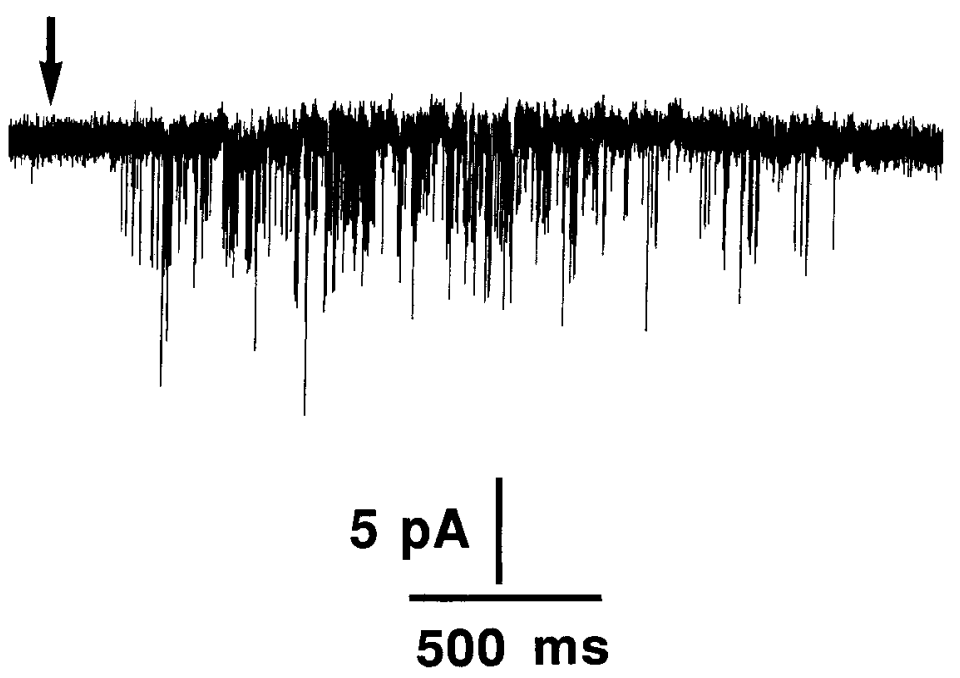

Figure 2. Response to odor stimulation. $A$, Response to a $150 \mathrm{msec}$ pulse of the odor mixture (delivered at the arrow). Four biphasic current transients due to action potentials invading the patch are followed by channel activity. $B$, Response to identical stimulus by the same cell after $\mathrm{NaCl}$ was replaced by choline, an ion that is not permeant, through either the odor-sensitive channel or the voltage-dependent sodium channel. The action potentials are absent and the channel activity is slightly reduced. $C$, Response to a $2 \mathrm{sec}$ pulse of odor beginning at the arrow with the cell still in the choline solution. Stronger stimulus gives intense channel activation. Pipette holding potential for all recordings was $40 \mathrm{mV}$. the odor-sensitive channel activity, voltage-dependent channels were activated in 9 of the 13 patches when the pipette voltage was commanded to potentials more negative than 0 (i.e., depolarizing potential levels).

Since olfactory neurons undergo membrane depolarization and generate action potentials in response to odors, the voltagegated channels in a patch were often activated by an odor. Figure $2 \mathrm{~A}$ shows a typical response to a $150 \mathrm{msec}$ pulse of odor stimulus. After a latency of nearly $125 \mathrm{msec}$, four largc, biphasic current transients due to action potentials were detected in the membrane patch followed by $1.5 \mathrm{sec}$ of intense channel activity during which up to three superpositions of inward currents can be seen. Some of this unclamped activity presumably resulted from the activation of voltage-gated channels within the patch by the action potential.

In order to avoid interference from these current transients and to ensure that the odor-activated currents were recorded at a constant intracellular potential, the cells were bathed in a solution in which choline completely replaced $\mathrm{Na}^{+}$. Choline does not permeate either the odor-sensitive conductance (Kurahashi, 1989) or the voltage-gated $\mathrm{Na}^{+}$conductance that underlies action potential generation (Firestein and Werblin, 1987), so the cells were unable to depolarize after receptor activation by odors. However, the patch of membrane sealed within the electrode remained in a solution high in $\mathrm{Na}^{+}$, so that channels located under the patch pipette and opened by intracellular factors would still conduct current. Figure $2 B$ shows the response to a 150 msec pulse of odor in the same cell as Figure $2 A$, but now with the choline Ringer's solution bathing the cell. The action potential current transients were absent, and the channel activity was somewhat reduced. In Figure $2 C$, a longer-lasting stimulation $(2 \mathrm{sec})$ was still able to elicit intense, odor-dependent channel activity. Similar results were obtained with a solution containing $2 \mathrm{mM} \mathrm{Cd}^{2+}$, also known to block the odor-sensitive 
A

$50 \mathrm{~ms}$

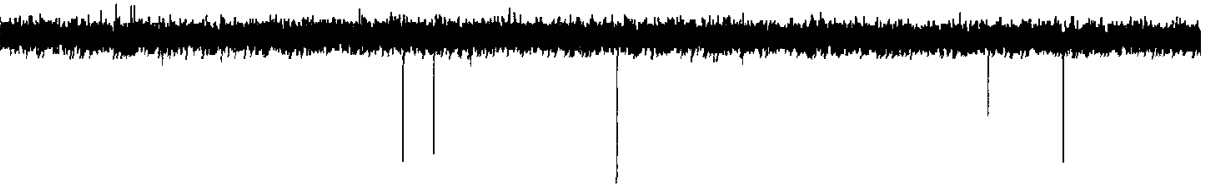

B

$250 \mathrm{~ms}$

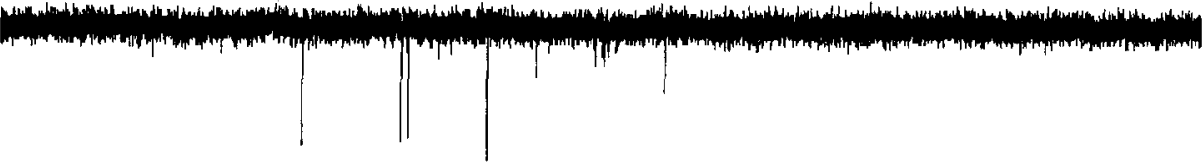

C

$500 \mathrm{~ms}$

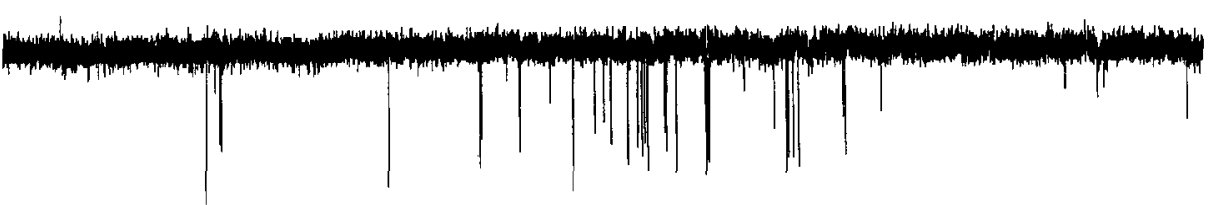

D

$750 \mathrm{~ms}$

Figure 3. Channel activity is locked to stimulus duration. Stimulus pulses of increasing duration elicited more activity and shorter latencies. The onset of the pulse was coincident with the beginning of the trace. Pulse duration is given at top right of each trace. Pipette holding potential, $40 \mathrm{mV}$.

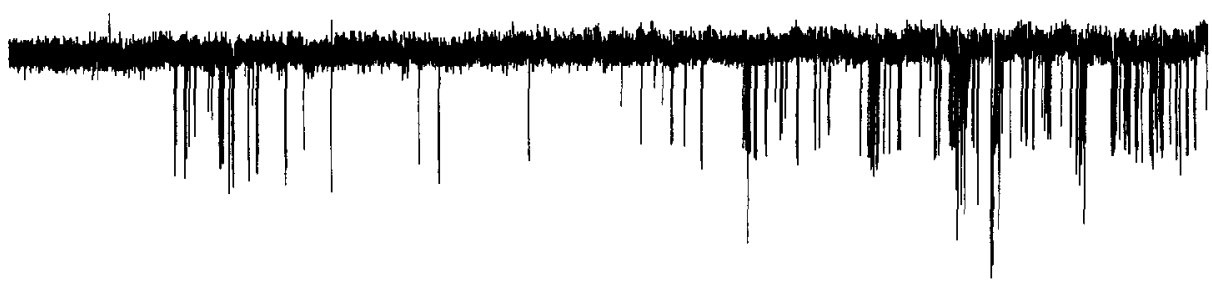

current (Kurahashi, 1989; Firestein et al., 1991), but the effect was difficult to reverse and $\mathrm{Cd}^{2+}$ was not used further. All experiments reported here were performed with the choline Ringer's solution.

After choline perfusion, the latency to the remaining channel activity was $632 \mathrm{msec}$ (Fig. $2 B$ ). The latency to the stronger stimulus pulse in Figure $2 C$ was only $150 \mathrm{msec}$. These times are on the order expected for cAMP to diffiuse from the cilia to channels located on the distal dendrite and knob, a distance estimated to be between 5 and $15 \mu \mathrm{m}$ (see Discussion). In different cells, the latency varied from $150 \mathrm{msec}$ to as much as 1.5 sec, depending on the strength of the stimulus, the geometry of the cell, and the location of the membrane patch. From these results, we concluded that membrane patches from the dendrite contained channels that could be activated by odor stimuli through an indirect intracellular pathway.

The channel activity was also correlated with both the con- centration and duration of the odor stimulus pulse, further suggesting that this channel is part of the transduction process. In Figure 3, responses from a single cell to stimulus pulses of 50 , 250,500 , and $750 \mathrm{msec}$ are shown. For increasing pulse durations between 50 and $500 \mathrm{msec}$, the concentration of ejected odor stimulus would be expected to increase with pulse length. Over this range, the number of openings increased, and the latency was reduced (from 1500 to $750 \mathrm{msec}$ ) as a function of increasing concentration. For pulses longer than $500 \mathrm{msec}$, the delivered concentration remains more or less constant. Nonetheless, a pulse of $750 \mathrm{msec}$ elicited increased channel activity as well as the activation of a second channel in the patch. The results are consistent with previous recordings of macroscopic currents showing that olfactory receptor neurons are sensitive to stimulus duration as well as to concentration, and that the odor-induced current is larger for longer-lasting stimuli of equal concentration (Firestein et al., 1990). 
A
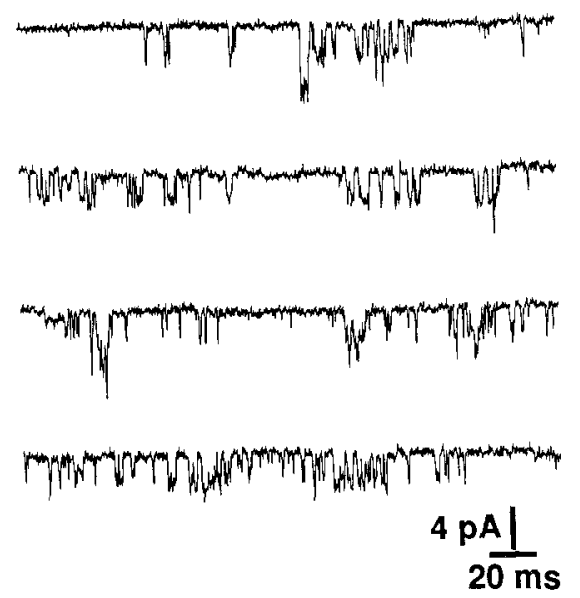

B

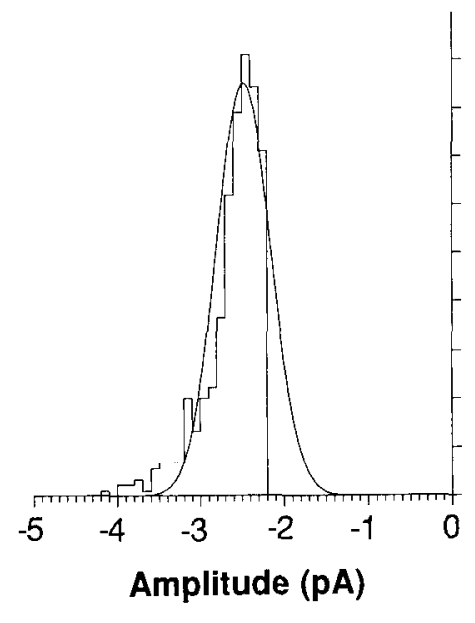

C

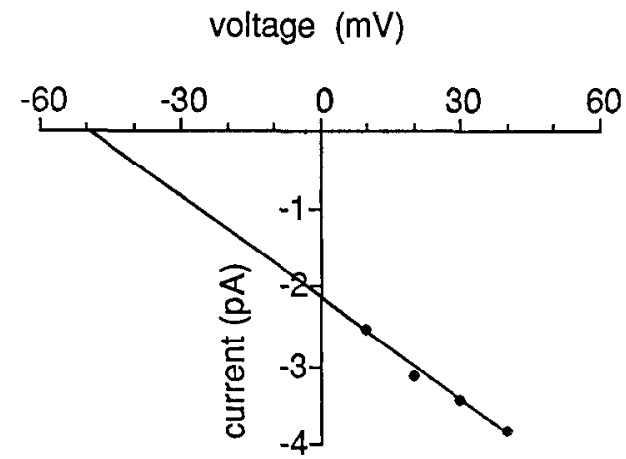

Figure 4. Odor-sensitive channels. $A$, Records of channel activity at a faster sweep speed show single-channel currents as well as up to three superpositions, indicating that there were at least three channels in this patch. Pipette holding potential, $30 \mathrm{mV}$. $B$, Amplitude histogram taken from several seconds of records such as those seen in $A$. Only portions of the record with single-channel openings were used. Peak mean current was $2.51 \mathrm{pA}$. Each division on the ordinate represents nine counts; total number of counts was 483 . Pipette potential, $10 \mathrm{mV}$. $C, I / V$ relation using peaks from amplitude histograms at pipette potentials of $10,20,30$, and $40 \mathrm{mV}$. Straight line extrapolates to $-50 \mathrm{mV}$, which is the approximate resting potential in these cells. The slope of the line gives a single-channel conductance of about $40 \mathrm{pS}$.

In order to attempt a first characterization of this channel, we utilized pulses of odor up to 3 sec long. In a few cells, this caused obvious desensitization, but in others this pulse duration was not a problem. A sampling of typical records on a fast time scale is shown in Figure 4A. Qualitatively, the channel openings displayed a burst type of behavior in which long closed periods were interrupted by bursts of openings with a flickery quality. The patch in this recording (Fig. $4 A$ ) contained at least two channels, and probable conductance substates were evident as well. Although the records from these experiments were briefer than the optimum, we were able to construct an amplitude histogram for purposes of comparing this channel with one clearly activated by cAMP (see below and the following article). The histogram (Fig. $4 B$ ) shows a major peak at about $-2.5 \mathrm{pA}$ with a pipette potential of $+10 \mathrm{mV}$.

In Figure $4 C$, an $I / V$ relation was determined from amplitude histograms constructed from responses to 1-3-sec-long stimulus pulses measured at four pipette potentials $(+10$ to $+40 \mathrm{mV})$. Unfortunately, it was impossible to obtain measurements outside this voltage range; at more positive pipette potentials (which strongly hyperpolarized the membrane patch) the membranc became unstable, and at more negative levels voltage-dependent channels were activated.

The four points were well fit by a straight line, suggesting an ohmic channel with a conductance of approximately $40 \mathrm{pS}$. The fitted line could be extrapolated to the zero current point, which intersected the voltage axis at about $-50 \mathrm{mV}$. This is the typical resting potential found in these neurons under whole-cell recording conditions (Trotier, 1986; Frings and Lindermann, 1988; Kurahashi, 1989; Firestein and Werblin, 1989), suggesting that the current through these channels reverses near $0 \mathrm{mV}$.

\section{Sensitivity of the channel to cyclic nucleotides}

If the odor-sensitive channels recorded here were the same as those underlying the previously identified cAMP-activated conductance of olfactory cilia, it would be expected that treatments that increase intracellular cAMP would also induce channel activity. We tested exogenously applied IBMX, a phosphodiesterase inhibitor, and 8-bromo cGMP, a membrane-permeable cyclic nucleotide, for these effects.

Figures 5 and 6 show results from these cxpcriments. In Figure 5 (left), a single channel in the patch was activated by a 500 msec pulse of odor (delivered at the arrow). After this trial, 100 $\mu \mathrm{M}$ IBMX, dissolved in the choline Ringer's solution to ensure that only the channel within the patch could be activated, was introduced by perfusion. Increased channel activity (Fig. 5, right) resulted within a few seconds of the onset of perfusion. The aclivily continued with no apparent adaptation for as long as the IBMX was present, up to $5 \mathrm{~min}$ in one experiment, and could be reversed by washing out the IBMX. This is consistent with data from whole-cell experiments in which IBMX at high concentrations elicited a several hundred picoampere current (Firestein et al., 1991), presumably due to nonstimulated, basal levels of activity of the adenylate cyclase. Similar results were obtained in three other cells with concentrations of IBMX between 100 and $500 \mu \mathrm{M}$, and in four cells with 8-bromo cGMP concentrations of $1 \mathrm{~mm}$ (Fig. 6A).

Figure 6 compares the channels activated by IBMX and cGMP. In both cases, the cell had been previously stimulated with odor stimuli and responded with channel activity similar to that seen in Figure 5. IBMX-activated channels are shown in Figure $6 \mathrm{~A}$, and Figure $6 B$ shows an amplitude histogram constructed from several seconds of these records. There was a unitary peak at $-2.9 \mathrm{pA}$ (pipetle potential of $+40 \mathrm{mV}$ ). This was similar to the results found for odor-sensitive channel activity (see above). As will be seen in the following article, it is also similar to the results in excised patches exposed to cyclic nucleotides.

Comparable findings were obtained using 8-bromo cGMP. Figure $6 C$ shows activity induced by exposure to $1 \mathrm{~mm} 8$-bromo cGMP in the bath. Within a few seconds of the onset of perfusion, channel activity increased dramatically, as was seen for IBMX. The amplitude histogram constructed from these data 


\section{ODOR}

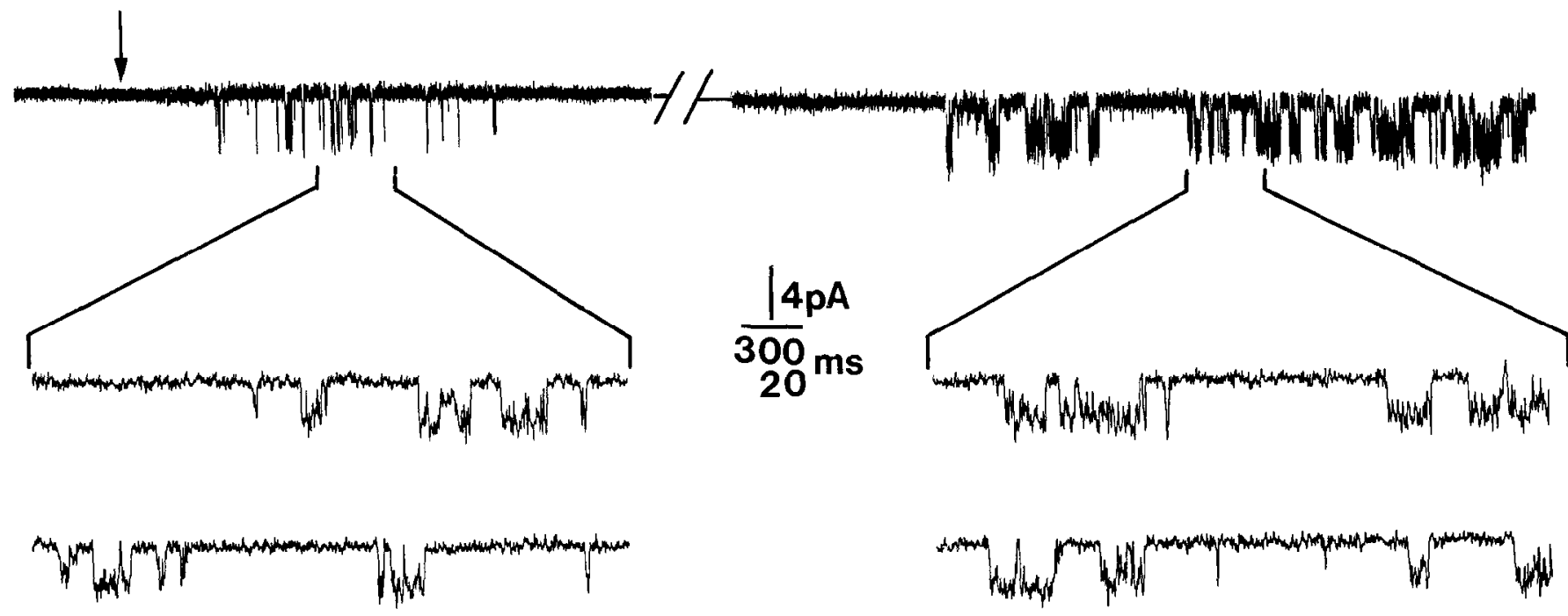

Figure 5. Odor- and cyclic nucleotide-induced single-channel activity in the same membrane patch. A 150 msec pulse of the odor stimulus delivered at the arrow elicited a burst of single-channel currents. Choline Ringer's solution with $100 \mu \mathrm{M}$ IBMX was then perfused into the bath, eliciting similar activity in the same patch of membrane. Sample records at higher sweep speeds are shown below. Time bar shows scale for slow and fast sweep speeds. Pipette potential, $40 \mathrm{mV}$.

(Fig. 6D) shows a mean peak current near $3 \mathrm{pA}$, indicating a channel with a unitary conductance of about $40 \mathrm{pS}$ (assuming a resting potential near $-50 \mathrm{mV}$ ). The corresponding adenosine analog, 8-bromo cAMP, was not effective in eliciting channel activity. This was consistent with our results utilizing wholecell recording techniques (Firestein et al., 1991).

Qualitatively, the channels activated by odor stimuli and by intracellular cyclic nucleotides appeared closely similar. Quantitatively, the amplitude histograms showed almost identical current levels (compare Figs. 4 and 6). In four patches that showed odor-sensitive channel activity, intracellular cyclic nucleotides also activated the channel. In two patches that did not show odor-induced channel activity, treatment with 8-bromo cGMP still elicited channel activity.

\section{Discussion}

Based on earlier reports that a similar or identical cyclic nucleotide-sensitive conductance could be found in membrane patches from the dendrite and soma (Trotier and MacLeod, 1986; Nakamura and Gold, 1987; Suzuki, 1989), we have undertaken to demonstrate that these channels are indeed those involved in the odor response. Utilizing the on-cell patch recording configuration, we have recorded activity in a small patch of membrane still attached to a responding receptor neuron, and with all its transduction machinery presumably intact. The correlation of channel activity with odor stimulation unequivocally identifies channels in the patch as the odor-sensitive conductance. The subsequent activation of these same channels by intracellular cyclic nucleotides is the first direct evidence that the ion channels underlying the odor-induced depolarization are the same as those activated by the cyclic nucleotide second messenger. These data provide an important link in the chain of events now thought to underlie olfactory signal transduction in vertebrates (Lancet et al., 1989).

The successful recording of odor-induced channel activity in nonciliary patches depends on the ability of second messengers, such as CAMP, to diffuse from the cilia to the region of patched membrane, and on the existence, within the patch, of one, or at most a few, ion channels sensitive to the second messenger. Fortunately, both of these conditions were fulfilled. Isolated cells provide some advantages since they tend to "round up" by retracting their dendrite. This has enabled us to place an electrode on the soma-dendrite very close to the origin of the cilia. Since the transduction-associated enzymes appear to be largely confined to the cilia (Pace et al, 1985; Bakalyar and Reed, 1990; Breer et al., 1990; Dhallan et al., 1990), one could imagine that cyclic nucleotides produced in the cilia easily diffuse into the distal dendrite. The $150 \mathrm{msec}$ to $1.5 \mathrm{sec}$ required for this to occur in our recordings seem to be reasonable times. For a diffusion coefficient of $4.4 \times 10^{-6} \mathrm{~cm}^{2} / \mathrm{sec}$ (Kurahashi, 1990), a molecule of cAMP would diffuse $10 \mu \mathrm{m}$ in $150 \mathrm{msec}$ and 35 $\mu \mathrm{m}$ in $1.5 \mathrm{sec}$. The cilia are $10-50 \mu \mathrm{m}$ in length, and the membrane patch was commonly $2-10 \mu \mathrm{m}$ from the base of the cilia so that the observed times were roughly what might be expected. The opposite situation, in which cAMP loaded into a wholecell patch pipette diffuses into the cell upon patch rupture, requires between $500 \mathrm{msec}$ and $1 \mathrm{sec}$ to induce a large inward current, a similar time course (Firestein et al., 1991).

It is not clear whether the existence of the odor-sensitive channel on the dendrite and soma occurs in vivo or whether it is the result of the isolation procedure. A similar situation is found in rod photoreceptors. There, the cGMP channel, which is responsible for the light-sensitive conductance (Fesenko et al., 1985; Matthews, 1987), exists at high concentrations on the outer segment, and also at low density in the inner segment membrane (Matthews and Watanabe, 1988). The parallel is particularly striking since the channels found in both the olfactory receptor and the photoreceptor are now known to share a high degree of sequence homology (Jones and Reed, 1989). The olfactory cilia and the rod outer segment are considered to be 
A

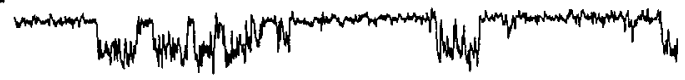

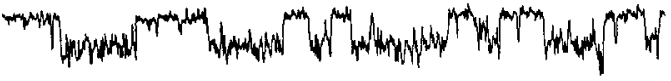

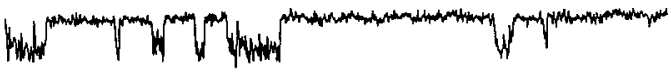

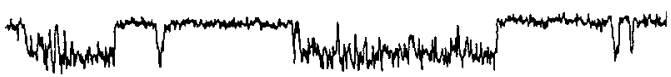

$4 \mathrm{pA}$ $2 \overline{\mathrm{ms}}$

C

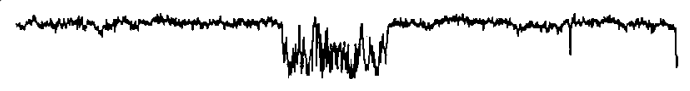

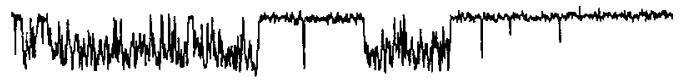
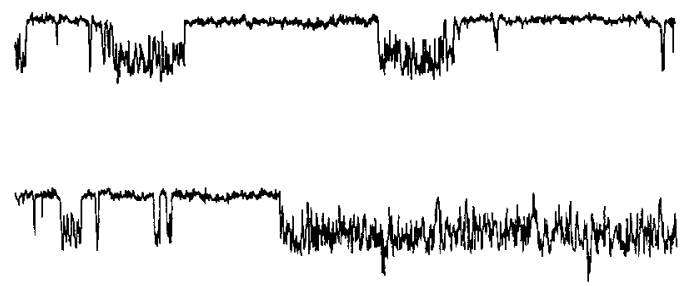

B

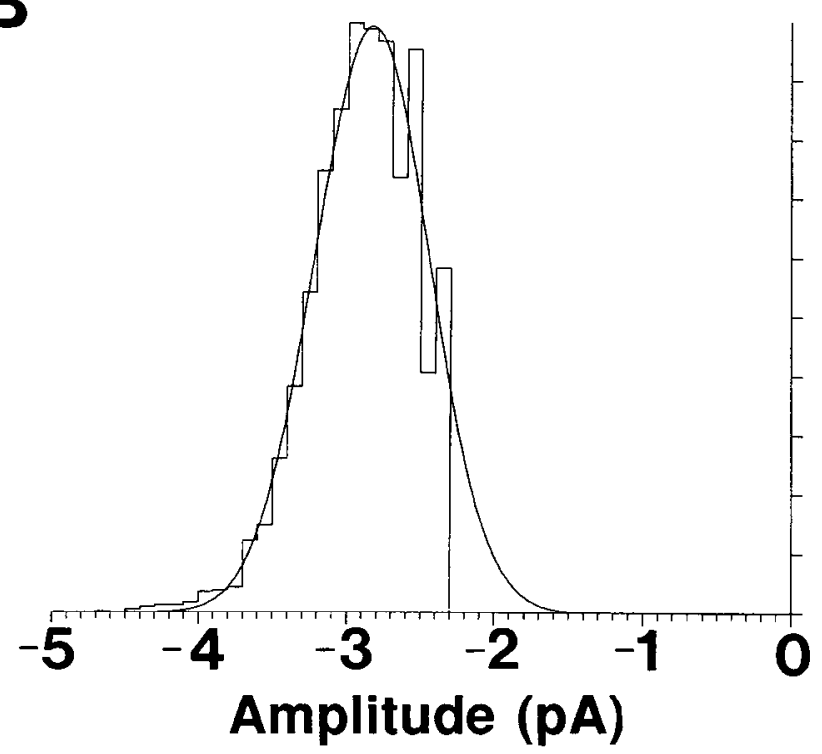

D

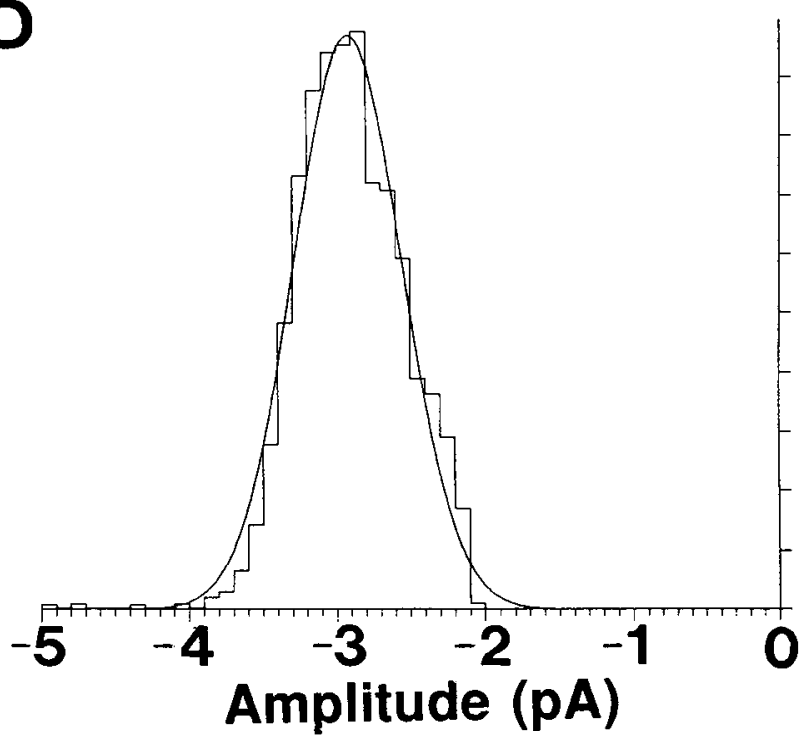

Figure 6. Comparison of single-channel currents elicited by IBMX and 8-bromo cGMP. A, Typical records of single-channel currents resulting from perfusion of the cell with $100 \mu \mathrm{M}$ IBMX. Records are not continuous but were chosen as a sample of the response. $B$, Amplitude histogram for the IBMX-induced currents. Mean peak current is $2.9 \mathrm{pA}$. Each division on the ordinate is 43 counts. Pipette potential, $20 \mathrm{mV}$. $C$, Typical currents elicited by $1 \mathrm{~mm} 8$-bromo cGMP. These records are not continuous but were chosen as representative. $D$, Amplitude histogram for the cyclic nucleotide-induced currents. Mean peak currents is $2.9 \mathrm{pA}$. Each division on the ordinate scale is 31 counts. Pipette potential, $20 \mathrm{mV}$.

homologous organelles. The physiological significance of sensory transduction channels in apparently nonsensory cellular regions has yet to be determined in either rods or olfactory neurons.

Whatever the underlying cause, it is clear that the occurrence of sensory channels at low densities in accessible cellular regions is of considerable experimental value for the analysis of sensory transduction in olfactory receptor neurons. The following article (Zufall et al., 1991) takes advantage of this to undertake an analysis of the cyclic nucleotide-gating characteristics of single channels. A more complete discussion of the implications of these results for the physiology of olfactory reception will be given in that article.

\section{References}

Bakalyar HA, Reed RR (1990) Identification of a specialized adenylyl cyclase that may mediate odorant detection. Science 250:1403-1406.

Breer H, Boekhoff I, Tarelius E (1990) Rapid kinetics of second messenger formation in olfactory transduction. Nature 344:65-68.

Dhallan RS, Yau KW, Schrader KA, Reed RR (1990) Primary structure and functional expression of a cyclic nucleotide-activated channel from olfactory neurons. Nature 347:184-187.

Fesenko EE, Kolesnikov SS, Lyubarsky AL (1985) Induction by cyclic GMP of cationic conductance in plasma membrane of retinal rod outer segment. Nature 313:310-313.

Firestein S, Werblin F (1987) Gated currents in isolated olfactory receptor neurons of the larval tiger salamander. Proc Natl Acad Sci USA 84:6292-6296. 
Firestein S, Werblin F (1989) Odor-induced membrane currents in vertebrate olfactory receptor neurons. Science 244:79-82.

Firestein S, Shepherd GM, Werblin FS (1990) Time course of the membrane current underlying sensory transduction in salamander olfactory receptor neurones. J Physiol (Lond) 430:135-158.

Firestein S, Darrow B, Shepherd GM (1991) Activation of the sensory current in salamander olfactory receptor neurons depends on a G-protein mediated cAMP second messenger system. Neuron 6:825-835.

Frings S, Lindemann B (1988) Odorant response of isolated olfactory receptor cells is blocked by amiloride. J Membr Biol 105:233-243.

Jones DT, Reed RR (1989) $\mathrm{G}_{\text {oll: }}$ : an olfactory neuron specific G-protein involved in odorant signal transduction. Science 244:790-795.

Kaupp UB, Tsutomu TN, Terada S, Bönigk W, Stühmer W, Cook NJ, Kangawa K, Matsuo H, Hirose T, Miyata T, Numa S (1989) Primary structure and functional expression from complementary DNA of the rod photoreceptor cyclic GMP-gated channel. Nature 342:762-766.

Kurahashi T (1989) Activation by odorants of cation-selective conductance in the olfactory receptor cell isolated from the newt. J Physiol (Lond) 419:177-192.

Kurahashi T (1990) The response induced by intracellular cyclic AMP in isolated olfactory receptor cells of the newt. J Physiol (Lond) 430: $355-371$.

Lancet D, Scahfir I, Pace U, Lazard D (1989) Receptor-activated chemosensory enzyme cascades. In: Chemical senses, Vol 1 (Brand JG, Teeter JH, eds), pp 283-298. New York: Dekker.

Matthews G (1987) Single channel recordings demonstrate that cGMP opens the light sensitive ion channel of the rod photoreceptor. Proc Natl Acad Sci USA 84:299-302.

Matthews G, Watanabe S-I (1988) Activation of single ion channels from toad retinal rod inner segments by cGMP: concentration dependence. J Physiol (Lond) 403:389-405.

Nakamura T, Gold GH (1987) A cyclic-nucleotide gated conductance in olfactory receptor cilia. Nature $325: 442-444$.

Pace U, Lancet D (1986) Olfactory GTP-binding protein: signal transducing polypeptide of vertebrate chemosensory neurons. Proc Natl Acad Sci USA 83:4947-4951.

Pace U, Hanski E, Salomon Y, Lancet D (1985) Odorant sensitive adenylate cyclase may mediate olfactory reception. Nature $316: 255$ 258.

Sakmann B, Neher E (1984) Patch clamp techniques for studying ionic channels in cxcitable membranes. Annu Rev Physiol 46:455-472.

Sklar PB, Anholt RRH, Snyder SH (1986) The odorant sensitive adenylate cyclase of olfactory receptor cells: differential stimulation by distinct classes of odorants. $J$ Biol Chem 261:15538-15543.

Suzuki N (1989) Voltage- and cyclic nucleotide-gated channels in isolated olfactory receptor cells. In: Chemical senses, Vol 1 (Brand JG, Teeter JH, Cagan RH, Kare MR, eds), pp 469-494. New York: Dekker.

Trotier D (1986) A patch clamp analysis of membrane currents in salamander olfactory cells. Pfluegers Arch 407:589-595.

Trotier D, MacLeod P (1983) Intracellular recordings from salamander olfactory receptor cells. Brain Res 268:225-237.

Trotier D, MacLeod P (1986) cAMP and cGMP open channels and depolarize olfactory receptor cells. Chem Senses 11:674.

Zufall F, Firestein S, Shepherd GM (1991) Analysis of single cyclic nucleotide-gated channels in olfactory receptor cells. J Neurosci 11: 3573-3580. 